\title{
Concise title: Maternal health service utilization
}

\author{
Md Akhtarul Islam*, Sutapa Dey Barna \\ Statistics Discipline, Khulna University, Khulna, 9208, Bangladesh
}

\section{A R T I C L E I N F O}

\section{Keywords:}

Maternal health services

Antenatal care

Skilled birth attendants

Postnatal care

Bangladesh

\begin{abstract}
A B S T R A C T
Objectives: The objective of this study is to identify the determinants and measure the trends in maternal healthfacility based utilization in Bangladesh. This research shows the importance of each variable and their role in utilizing maternity care in Bangladesh.

Materials and methods: In our study, we have analysed BDHS 2004, 2007, 2011 and 2014 data to measure the determinants and trends in maternal health services in Bangladesh, using the binary logistic regression model. Results: Our study revealed that the variable education of women, place of residence, wealth index, and husband's education have a significant association with the maternal health services utilization. Women who completed higher education were more likely to use antenatal care (AOR $=3.76$, CI $=2.07-6.52$ ), skilled birth attendants $(\mathrm{AOR}=2.82, \mathrm{CI}=1.96-1.4 .08)$ and postnatal care $(\mathrm{AOR}=1.87, \mathrm{CI}=1.31-2.68)$. Women from urban areas were more likely to use ANC (AOR $=1.30, \mathrm{CI}=1.05-1.60)$, SBAs (AOR $=1.64,9 \mathrm{CI}=1.40-1.92)$ and PNC services ( $\mathrm{AOR}=1.45, \mathrm{CI}=1.23-1.70)$ than women from rural areas. Women from the richest households were more likely to use ANC ( $\mathrm{AOR}=2.30, \mathrm{CI}=1.80-2.95)$, $\mathrm{SBAs}(\mathrm{AOR}=2.23, \mathrm{CI}=1.83-2.71$ ) and PNC $(\mathrm{AOR}=1.78, \mathrm{CI}=1.47-2.16)$ than poor women.

Conclusion: Maternal health service utilization should be more targeted towards the rural women in Bangladesh as there seems a high inconsistency in service utilization among urban and rural mothers. ANC is an essential entry point for the ensuing application of delivery and PNC services. So, it is recommended to promote women's education and empowerment with improved geographical access and strong ANC policies.
\end{abstract}

\section{Introduction}

In developing countries, a remarkable number of women experience life-threatening and other serious health problems related to pregnancy or childbirth as complications of pregnancy and childbirth cause more deaths and disability compared to other reproductive health problems. ${ }^{1}$ Having around $10 \%$ of pregnancies are at high-risk, there are about 500 maternal deaths for every 100,000 live births and maternal mortality is on average 18 times higher in developing countries compared to developed countries. $^{2}$ Although by 2015 , maternal mortality had decreased by over $40 \%$ from the 1990 levels, the utilization of health services is still far below any acceptable standard. ${ }^{1,4}$ To diminish maternal mortality ratio United Nations' (UN) Millennium Development Goals (MDGs) have set a target, also, to curtail maternal mortality ratio to less than 70 per 100,000 live births by 2030 one of the health goals of the UN's Sustainable Development Goals (SDGs) SDG 3.1 is intended. ${ }^{3}$

In spite of getting government's commitment to delivering health facilities to the doorsteps of common people through Essential Service Package (ESP), the situation is still worse in Bangladesh due to the lack of accessibility in modern health service and poor utilization. ${ }^{4}$ It has one of the highest maternal mortality rates (MMR) in worlds i.e. 3/1000 live birth and the child and infant mortality is 52/1000 live births and $14 / 1000$ children respectively. ${ }^{5,6}$ Each year in Bangladesh, about 6000 women die from pregnancy-related complications, on the other hand, about 194,000 women suffer from injuries or disabilities caused by complications during pregnancy and childbirth. ${ }^{7,8}$ Maternal mortality ratio (MMR) (170 per 100,000 live births) and neonatal mortality rate (NMR) (28 per 1000 live births) are still considerably high in Bangladesh although it has made remarkable progress in achieving the targets for Millennium Development Goals (MDGs) 4 and 5. Low utilization of maternal health services such as antenatal care (ANC), skilled birth attendance (SBA) at delivery and postnatal care (PNC) are one of the major reasons for these high mortality rates. ${ }^{8,9}$

Currently, $71 \%$ of women worldwide utilize ANC services; and in industrialized countries, it is $95 \%$, in South Asian countries it is $54 \%$ and in Sub Saharan African countries it is $64 \% .^{10}$ In Bangladesh, the proportion of women receiving at least one antenatal visit from a medically trained provider rose from $28 \%$ in the early 1990 s to $64 \%$ in 2014 and approximately 1 in 3 women i.e. $31 \%$ currently receives the

\footnotetext{
${ }^{*}$ Corresponding author.

E-mail addresses: akhtarulstat@ku.ac.bd (M.A. Islam), sutapaborna.ku@gmail.com (S.D. Barna).
} 
Table 1

The frequency table of different study variables.

\begin{tabular}{|c|c|c|c|c|c|}
\hline Variables & Frequency & Percent (\%) & Variables & Frequency & Percent (\%) \\
\hline Antenatal care & & & Wealth index & & \\
\hline No antenatal & 2507 & 23.9 & Poor & 3400 & 32.4 \\
\hline ANC & 7981 & 76.1 & Middle & 1873 & 17.9 \\
\hline Skilled birth attendant & & & Rich & 5215 & 49.7 \\
\hline Unskilled & 6004 & 57.2 & Birth order number & & \\
\hline Skilled & 4484 & 42.8 & First birth & 3746 & 35.7 \\
\hline Postnatal care & & & More than one & 6742 & 64.3 \\
\hline No & 3533 & 33.7 & Age of respondent at first birth & & \\
\hline Yes & 6955 & 66.3 & $\leq 19$ & 1582 & 15.1 \\
\hline Type of place of residence & & & $20-25$ & 4083 & 38.9 \\
\hline Urban & 4025 & 38.4 & More than 25 & 4823 & 46.0 \\
\hline Rural & 6463 & 61.6 & Reading newspaper & & \\
\hline Region & & & No & 8280 & 78.9 \\
\hline Barisal & 1215 & 11.6 & Yes & 2208 & 21.1 \\
\hline Chittagong & 2144 & 20.4 & Listening radio & & \\
\hline Dhaka & 1917 & 18.3 & No & 8880 & 84.7 \\
\hline Khulna & 1350 & 12.9 & Yes & 1608 & 15.3 \\
\hline Rajshahi & 1514 & 14.4 & Watching television & & \\
\hline Rangpur & 1587 & 15.1 & No & 3801 & 36.2 \\
\hline Sylhet & 761 & 7.3 & Yes & 6687 & 63.8 \\
\hline Respondents education & & & Body mass index & & \\
\hline No education & 1898 & 18.1 & Under-weight & 2619 & 25.0 \\
\hline Primary & 2768 & 26.4 & Normal & 6142 & 58.6 \\
\hline Secondary & 4472 & 42.6 & Over-weight & 1727 & 16.5 \\
\hline Higher & 13.50 & 12.9 & Person who take health decision & & \\
\hline Husbands education & & & Women, women with husbands or others & 6445 & 61.5 \\
\hline No education & 2541 & 24.2 & Husband or others & 4043 & 38.5 \\
\hline Primary & 2768 & 26.4 & Year of interview & & \\
\hline Secondary & 3247 & 31.0 & 2004 & 931 & 8.9 \\
\hline Higher & 1932 & 18.4 & 2007 & 3253 & 31.0 \\
\hline Respondents work status & & & 2011 & 3352 & 32.0 \\
\hline Jobless & 8461 & 80.7 & 2014 & 2952 & 28.1 \\
\hline Working & 2027 & 19.3 & & & \\
\hline
\end{tabular}

recommended four or more ANC visits. ${ }^{11}$ To minimize maternal deaths significantly, birth attendance by SBAs is regarded as an important factor because, in Bangladesh, the application of SBAs at birth is entirely shallow. ${ }^{12,13}$ Here, only one is performed by SBAs among the five deliveries and the portion even gets lower especially in the slum and tribal areas. ${ }^{14,15}$

Furthermore, Timely and adequate postnatal care (PNC) during this critical period can potentially make a significant difference in their survival rate because almost maximum maternal deaths happen in the first week after delivery. ${ }^{16-18}$ Although it is recommended by the World Health Organization (WHO) that all women where they deliver receive PNC in the first $24 \mathrm{~h}$, the first two days are frequently identified as the ideal time for postnatal checking. ${ }^{19}$

It is shown in developing countries that the use of health care services is not only related to the availability, quality and cost of services but also the social structure, health beliefs and personal characteristics of the users. ${ }^{20}$ The objectives of this research are to identify factors that affect the utilization of Antenatal Care (ANC), use of Skilled Birth Attendants (SBAs) and Postnatal Care (PNC) services in Bangladesh; determine the impact of influencing factors on antenatal care, skilled delivery, and postnatal care services and find out the adjusted odds ratio to observe which maternity stages were given importance in Bangladesh through logistic regression.

\section{Materials \& methods}

\subsection{Data source}

The data that have been used in this research was extracted from the Bangladesh Demographic and Health Survey (BDHS 2004, 2007, 2007, 2014). ${ }^{21-24}$

\subsection{Variables of the study}

\subsubsection{Dependent variables}

Antenatal Care $(0=$ No antenatal care, $1=$ Received antenatal care) is the routine health control of presumed healthy pregnant women without symptoms, to diagnose diseases or complicating obstetric conditions without symptoms, and to provide information regarding lifestyle, pregnancy, and delivery. ${ }^{25}$

For Skilled Birth Attendance we have taken into account place of delivery $[0=$ Unskilled (Home/Relatives home, $1=$ skilled (Hospital/ clinic/private NGO/community clinic))] as our dependent variable. The emergence of a skilled birth attendant at delivery is monumental in averting maternal and neonatal mortality and morbidity. It has currently shown that even well-learned traditional birth attendants (TBAs) cannot, in most cases, save women's lives successfully because they are unable to treat complexity, and are often unable to prescribe. ${ }^{26}$

Postnatal Care ( $0=$ Not received, $1=$ Received postnatal care) begins immediately after the birth of a child as the mother's body, including hormone levels and uterus size, returns to a non-pregnant state. The terms puerperal period or immediate postpartum period are commonly used to refer to the first six weeks following childbirth. ${ }^{27}$

\subsubsection{Independent variables}

A set of socioeconomic and demographic factors for the determination of place of delivery were purposively selected as independent variables based on previous literature. A test of association was conducted to check whether they were significantly associated with the dependent variable or not. Later on, only significantly associated variables were selected for logistic regression. Beginning with type of place of residence, remained same as they were in original datasets ( 1 = Urban, 2 = Rural). Respondent education and Husband's education also remained same as they were in original dataset ( $1=$ Illiterate, 2 = Primary, $3=$ Secondary, $4=$ Higher). For the variable Wealth 
Table 2

Percentage of women who had at least one birth in the five years preceding the survey who received ANC, skilled birth and PNC service by background characteristics.

\begin{tabular}{|c|c|c|c|}
\hline Variables & $\begin{array}{l}\text { Received } \\
\text { SBAs }\end{array}$ & Received PNC & Received ANC \\
\hline \multicolumn{4}{|l|}{ Types of places of residence } \\
\hline Urban & $57.8 \%$ & $74.9 \%$ & $86.5 \%$ \\
\hline Rural & $33.4 \%$ & $60.9 \%$ & $69.6 \%$ \\
\hline \multicolumn{4}{|l|}{ Region } \\
\hline Barisal & $35.8 \%$ & $62.8 \%$ & $71.2 \%$ \\
\hline Chittagong & $36.2 \%$ & $65.7 \%$ & $76.1 \%$ \\
\hline Dhaka & $45.4 \%$ & $65.8 \%$ & $75.4 \%$ \\
\hline Khulna & $59.3 \%$ & $76.1 \%$ & $81.5 \%$ \\
\hline Rajshahi & $43.9 \%$ & $66.1 \%$ & $79.5 \%$ \\
\hline Rangpur & $33.9 \%$ & $56.1 \%$ & $71.5 \%$ \\
\hline Sylhet & $52.3 \%$ & $79.2 \%$ & $79.1 \%$ \\
\hline \multicolumn{4}{|l|}{ Respondents education } \\
\hline No education & $13.2 \%$ & $42.6 \%$ & $47.8 \%$ \\
\hline Primary & $27.1 \%$ & $56.1 \%$ & $67.5 \%$ \\
\hline Secondary & $53.5 \%$ & $75.6 \%$ & $86.9 \%$ \\
\hline Higher & $80.6 \%$ & $89.9 \%$ & $97.6 \%$ \\
\hline \multicolumn{4}{|l|}{ Husbands education } \\
\hline No education & $19.1 \%$ & $48.3 \%$ & $55.5 \%$ \\
\hline Primary & $32.5 \%$ & $60.2 \%$ & $70.5 \%$ \\
\hline Secondary & $51.1 \%$ & $73.6 \%$ & $85.7 \%$ \\
\hline Higher & $74.6 \%$ & $86.5 \%$ & $95.1 \%$ \\
\hline \multicolumn{4}{|l|}{ Respondents work status } \\
\hline Jobless & $45.1 \%$ & $67.4 \%$ & $77.3 \%$ \\
\hline Working & $32.8 \%$ & $61.6 \%$ & $70.9 \%$ \\
\hline \multicolumn{4}{|l|}{ Wealth index } \\
\hline Poor & $21.3 \%$ & $51.9 \%$ & $58.6 \%$ \\
\hline Middle & $34.9 \%$ & $62.5 \%$ & $72.5 \%$ \\
\hline Rich & $59.5 \%$ & $77.1 \%$ & $88.8 \%$ \\
\hline \multicolumn{4}{|l|}{ Birth order number } \\
\hline First birth & $58.8 \%$ & $77.9 \%$ & $86.2 \%$ \\
\hline More than one & $33.8 \%$ & $59.8 \%$ & $70.5 \%$ \\
\hline \multicolumn{4}{|l|}{ Age of respondent at first birth } \\
\hline Less than equal 19 & $46.4 \%$ & $71.4 \%$ & $79.7 \%$ \\
\hline $20-25$ & $44.5 \%$ & $68.3 \%$ & $79.1 \%$ \\
\hline More than 25 & $40.1 \%$ & $62.9 \%$ & $72.4 \%$ \\
\hline \multicolumn{4}{|l|}{ Reading newspaper } \\
\hline No & $36.4 \%$ & $62.0 \%$ & $71.4 \%$ \\
\hline Yes & $66.6 \%$ & $82.6 \%$ & $93.6 \%$ \\
\hline \multicolumn{4}{|l|}{ Listening radio } \\
\hline No & $44.7 \%$ & $66.5 \%$ & $76.3 \%$ \\
\hline Yes & $32.2 \%$ & $65.5 \%$ & $75.0 \%$ \\
\hline \multicolumn{4}{|l|}{ Watching television } \\
\hline No & $23.1 \%$ & $52.0 \%$ & $59.9 \%$ \\
\hline Yes & $53.9 \%$ & $74.4 \%$ & $85.3 \%$ \\
\hline \multicolumn{4}{|l|}{ Body mass index } \\
\hline Under-weight & $27.6 \%$ & $56.1 \%$ & $66.1 \%$ \\
\hline Normal & $41.1 \%$ & $65.6 \%$ & $76.0 \%$ \\
\hline Over-weight & $71.6 \%$ & $84.2 \%$ & $91.8 \%$ \\
\hline \multicolumn{4}{|c|}{ Person who take health decision } \\
\hline $\begin{array}{l}\text { Women, women with husbands } \\
\text { and others }\end{array}$ & $45.3 \%$ & $67.1 \%$ & $78.2 \%$ \\
\hline Husband only or orthers & $38.6 \%$ & $65.1 \%$ & $72.8 \%$ \\
\hline \multicolumn{4}{|l|}{ Year of interview } \\
\hline 2004 & $64.9 \%$ & $71.3 \%$ & $87.9 \%$ \\
\hline 2007 & $57.5 \%$ & $72.9 \%$ & $88.8 \%$ \\
\hline 2011 & $39.0 \%$ & $66.8 \%$ & $76.0 \%$ \\
\hline 2014 & $23.8 \%$ & $57.0 \%$ & $58.5 \%$ \\
\hline
\end{tabular}

Index, poorest and poorer constructed poor $=1$, category middle as middle $=2$ and the rest other categories constituted rich $=3$. Categories for birth order were 1st order with one birth $=1$ and rest birth orders formed other order $=2$. Age of respondent at first birth is categorized as less than or equal $19=1,20-25=2$, more than $25=3$. Reading newspaper, Watching TV and Listening ration variable are categories in to two categories Yes $=1$, and No $=2$. Respondent's work status $(1=$ Jobless, $2=$ Working) and Region's (Barisal $=1$, Chittagong $=2$, Dhaka $=3$, Khulna $=4$, Rajshahi $=5$, Rangpur $=6$, Sylhet $=7$ ) categories remain same as the original data set. Person who take health decision is categorized as Women, women with husbands or others $=1$, and Husband or others $=2$ and the variable Year of interview as $2004=1,2007=2,2011=3,2014=4$. Finally for body mass index, worldwide commonly accepted BMI ranges are: underweight $=2$ (under $18.5 \mathrm{~kg} / \mathrm{m}^{2}$ ), normal weight $=1\left(18.5-25 \mathrm{~kg} / \mathrm{m}^{2}\right)$, over weight $=3$ (over $25 \mathrm{~kg} / \mathrm{m}^{2}$ ).

\subsection{Binary logistic regression}

Bivariate analysis (Pearson's $\chi 2$ ) was performed to assess the relationship between the dependent and independent variables. In order to find the influencing factors for utilizing maternal healthcare services among pregnant women, we used logistic regression. ${ }^{28}$ As we categorize the outcome variable into two categories, binary logistic regression (BLR) is used to estimate the association to provide a clearer idea about how intensely different factors influence the outcome. Logistic regression generates the coefficients (and its standard errors and significance levels) of a formula to predict a logit transformation of the probability of presence of the characteristic of interest:

logit $(p)=b_{0}+b_{1} X_{1}+b_{2} X_{2}+\ldots+b_{k} X_{k}$

where, $\mathrm{p}$ is the probability of presence of the characteristic of interest. The logit transformation is defined as the logged odds:

Odds $=\frac{p}{1-p}=\frac{\text { Probality of presence of characteristic }}{\text { Probality of absence of charecteristic }}$

And

$\operatorname{logit}(p)=\log \log \left(\frac{p}{1-p}\right)$

Rather than choosing parameters that minimize the sum of squared errors (like in ordinary regression) estimation in logistic regression chooses parameters that maximize the likelihood of observing the sample values.

\section{Results}

From Table 1 we find that, among the respondents, $76.1 \%$ had at least one ANC visit, Only $42.8 \%$ of the respondent had skilled birth attendant and $66.3 \%$ of the respondents had PNC visits after their delivery. Among the respondents, $61.6 \%$ was from rural areas and $38.4 \%$ lived in urban areas. Chittagong having the highest respondent $20.4 \%$, Dhaka was the second highest region with $18.3 \%$ respondent whereas only $7.3 \%$ was from Sylhet. We can see from the table that, most of the respondents had completed their secondary educational level, numerically $42.6 \%$ but only $12.9 \%$ had higher education and $18.1 \%$ women were illiterate. On the contrary, $24.2 \%$ of the husbands of respondents were illiterate and $31 \%$ and $18.4 \%$ had secondary and higher educational background respectively.

Majority of the women being jobless (80.7\%), 32.4\% women were from poor family and $64.3 \%$ respondents have more than one child. The table shows that, $46 \%$ respondent aged more than 25 years at the time of their first pregnancy, 38.9\% of the respondents aged between 20 and 25 years. The practice of reading newspaper watching TV and listening to ratio is $21.1 \%, 63.8 \%$ and $15.3 \%$ respectively. Majority of the respondent having normal weight (58.6\%) and $61.5 \%$ of the women used to take the health care decisions about themselves or with their husbands. Again in Table 2 we can see the independent variables categories within dependent variable.

From Table 3, it is revealed that in case of the variable listening to radio, the p-value is 0.480 for ANC and for PNC it is 0.263 which indicate that it is not strongly associated. But except this one, for the remaining indicators, the p-values showed strong associations with dependent variables.

From Table 4 we can say that the women's place of residence is significantly associated with the practice of receiving ANC, PNC and 
Table 3

The association between dependent variables and independent variables.

\begin{tabular}{|c|c|c|c|c|c|c|}
\hline \multirow[t]{2}{*}{ Variables } & \multirow{2}{*}{$\frac{\text { SBAs }}{\chi^{2} \text { test }}$} & \multirow[t]{2}{*}{ P-Value } & \multirow{2}{*}{$\frac{\text { PNC }}{\chi^{2} \text { test }}$} & \multirow[t]{2}{*}{ P-Value } & \multirow{2}{*}{$\frac{\text { ANC }}{\chi^{2} \text { test }}$} & \multirow[t]{2}{*}{ P-Value } \\
\hline & & & & & & \\
\hline Types of places of residence & 605.279 & .000 & 217.151 & .000 & 389.346 & .000 \\
\hline Year of interview & 929.394 & .000 & 188.291 & .000 & 862.830 & .000 \\
\hline Region & 297.053 & .000 & 195.297 & .000 & 70.037 & .000 \\
\hline Respondents education & 1954.280 & .000 & 1115.759 & .000 & 1575.897 & .000 \\
\hline Husbands education & 1594.987 & .000 & 845.092 & .000 & 1187.296 & .000 \\
\hline Respondents work status & 101.565 & .000 & 24.801 & .000 & 36.696 & .000 \\
\hline Wealth index & 1285.367 & .000 & 602.180 & .000 & 1049.054 & .000 \\
\hline Birth order number & 611.741 & .000 & 353.198 & .000 & 328.672 & .000 \\
\hline Age of respondent at first birth & 27.061 & .000 & 50.728 & .000 & 67.229 & .000 \\
\hline Reading newspaper & 648.506 & .000 & 332.433 & .000 & 469.394 & .000 \\
\hline Listening radio & 86.199 & .000 & .500 & .480 & 1.255 & .263 \\
\hline Watching television & 943.456 & .000 & 543.817 & .000 & 856.404 & .000 \\
\hline Body mass index & 839.602 & .000 & 370.883 & .000 & 380.421 & .000 \\
\hline Person who take health decision & 45.606 & .000 & 4.339 & .037 & 40.078 & .000 \\
\hline
\end{tabular}

SBA services. Women in rural areas were $35.8 \%$ less likely to use skilled birth attendants than the women from the urban area. Women of 2014 were $288.7 \%, 744.8 \% 261.1 \%$ more likely to use ANC, PNC and SBAs respectively compared to the women from 2004. Compared with the respondents with no educational background, the ones with primary to higher education were more likely to take all the facilities and among them, respondents who completed higher education were $710 \%$ more likely to take ANC visits than illiterate ones and for receiving SBA and PNC, it was $464.9 \%$ and $277.8 \%$ higher respectively than women with no education. Husband's education also showed similar results except, husbands with primary education showed an insignificant association with the use of PNC visits of their wives. Surprisingly, the working women were $32.8 \%$ less likely to utilize skilled birth attendance and were found insignificant for receiving ANC and PNC. The rich respondents were more likely to receive ANC and SBA facilities than the poor ones and middle class showed insignificant associations. Respondents who gave birth to more than one child were less likely to receive the facilities than their first time. Age of the respondent at their first birth was found significant only for taking skilled birth attendant and respondents who aged more than 25 years were $26.5 \%$ more likely to take skilled birth attendance than the ones who aged 19 years or less. Regarding the use of ANC visits, respondents who read newspapers were $54.5 \%$ more likely to receive this facility than women who did not read the newspaper. The three facilities were more likely to be taken by the women who watched television than the ones who did not. Compared to normal weighed women, under-weighed women were less likely and over-weighed women were more likely to receive the facilities. When the health care decisions were taken by husbands only or others, they were less likely in support of their wives, taking ANC and SBA facilities than decisions taken by women only or along with their husbands and others.

\section{Discussion}

Findings of our study showed how equity in maternal healthcare utilization has changed in last decade and whether the patterns are different in urban and rural areas. It is observed that while the urban poor are increasingly availing of health facilities for antenatal care, skilled birth attendants and postnatal care, the rural poor are still lagging behind. ${ }^{29,31}$ A study by Mohammad Hajizade and colleagues found that there was also visible variation in different regions in Bangladesh which is similar to our study. ${ }^{30}$ Here, it is clearly depicted that there is always a significant association between educated women and access of utilization in health services as higher educated women always lead in getting ANC, SBA and PNC services compared to those who have no education or even if having primary or secondary education. Though the effect of maternal education level is stronger than husband's education, husbands' knowledge and involvement is related to women's access in all the three services. ${ }^{32}$ Since husbands are key decision-makers in households, especially in developing countries, health care decisions for their wives taken by them alone are less likely than decisions taken by their wives only or along with him/family in support of taking ANC, SBA and PNC facilities. ${ }^{33}$ Respondent who take their health care utilization decision alone or with their husband are more likely to access in ANC, SBA and PNC facilities compared to others which is supported with other studies. ${ }^{34,35}$ Our study is consistent with the result in Uganda and Nepal that women from poor family background are less likely to take maternal health care services compare to women from rich family background. ${ }^{34-36}$ Women who give birth to more than one child are less likely to get extra facilities than those who give birth for the first time. This may be due to the fact that women who have higher parity gain more confidence to stay at home for delivery and less interested to take the skilled birth attendant's help. Other similar studies found that as the number of children born increased there occurs low likelihood of having health facility. ${ }^{37}$ This study found that for the first birth whose age are 25 or more are more likely to get skilled birth attendant facility than the respondents who are 19 or lower that is older women are more likely to seek maternal health-care services than younger women. ${ }^{38}$ There is a remarkable effect of BMI on health utilization. This study found that compared to normal weighted women, under-weighted women are less likely and overweight women are more likely to receive those facilities. A study in the USA found that women with an obese BMI accessed care 0.2 weeks later than women with a recommended BMI and similar to our findings. ${ }^{39,40}$ The awareness of people on maternal health and other issues could be increased by using public media sources like watching television and reading newspapers. In case of using ANC, women who read newspapers regularly are willing to get ANC facility compared to those who don't have this habit. Similarly, the respondents who watch television are more likely to receive all three facilities. A Nigeria-based study found that there is a strong association between community media and maternal health service utilization. ${ }^{41}$

\section{Conclusion}

This study made an attempt to find out the factors associated with maternal health care services in Bangladesh. We have found that the utilization of maternal health care services have increased over the last decade. It is revealed that women and their husband's education, wealth index are the most important determinants of the use of maternal health services. Moreover, the inequalities of facilities/services are clearly shown in this research for urban and rural people. The women from 
Table 4

Adjusted odds ratios and 95\% confidence intervals for receiving ANC, SBAs and PNC services in Bangladesh.

\begin{tabular}{|c|c|c|c|c|c|c|c|c|c|}
\hline \multirow[t]{2}{*}{ Variables } & \multicolumn{3}{|c|}{ Received ANC } & \multicolumn{3}{|c|}{ Take SBAs } & \multicolumn{3}{|c|}{ Use of PNC } \\
\hline & \multicolumn{2}{|c|}{ Adjusted OR (95\% CI) } & \multirow[t]{2}{*}{ P-value } & \multicolumn{2}{|c|}{ Adjusted OR (95\% CI) } & \multirow[t]{2}{*}{ P-value } & \multicolumn{2}{|c|}{ Adjusted OR (95\% CI) } & P-value \\
\hline \multicolumn{8}{|c|}{ Types of places of residence } & & \\
\hline Urban & 1.00 & & & 1.00 & & & 1.00 & & \\
\hline Rural & .624 & $.551-.707$ & .000 & .642 & $.579-.712$ & .000 & .804 & $.724-.892$ & .000 \\
\hline \multicolumn{10}{|l|}{ Year of Interview } \\
\hline 2004 (ref.) & 1.00 & & & 1.00 & & & 1.00 & & \\
\hline 2007 & .725 & $.567-.927$ & .010 & .430 & $.357-.518$ & .000 & .664 & $.552-.798$ & .000 \\
\hline 2011 & 1.832 & $1.39-2.42$ & .000 & 1.069 & $.886-1.29$ & .487 & 1.077 & $.814-1.42$ & .000 \\
\hline 2014 & 3.887 & $2.79-5.42$ & .000 & 3.611 & $2.76-4.72$ & .000 & 8.448 & $5.99-11.9$ & .000 \\
\hline \multicolumn{10}{|l|}{ Region } \\
\hline Barisal & 1.00 & & & 1.00 & & & 1.00 & & \\
\hline Chittagong & 1.134 & $.944-1.36$ & .179 & .885 & $.743-1.06$ & .173 & 1.059 & $.902-1.245$ & .483 \\
\hline Dhaka & 1.135 & $.939-1.372$ & .190 & 1.425 & $1.19-1.71$ & .000 & 1.066 & $.902-1.245$ & .455 \\
\hline Khulna & 1.391 & $1.129-1.713$ & .002 & 2.562 & $2.12-3.09$ & .000 & 1.609 & $1.338-1.935$ & .000 \\
\hline Rajshahi & 1.717 & $1.404-2.099$ & .000 & 1.510 & $1.25-1.82$ & .000 & 1.118 & $.940-1.329$ & .209 \\
\hline Rangpur & 1.377 & $1.139-1.664$ & .001 & 1.223 & $1.01-1.48$ & .035 & .899 & $.761-1.064$ & .215 \\
\hline Sylhet & 1.442 & $1.130-1.840$ & .003 & 2.041 & $1.64-2.55$ & .000 & 2.379 & $1.896-2.984$ & .000 \\
\hline \multicolumn{10}{|c|}{ Respondents education } \\
\hline No education & 1.00 & & & 1.00 & & & 1.00 & & \\
\hline Primary & 1.759 & $1.539-2.010$ & .000 & 1.752 & $1.47-2.08$ & .000 & 1.336 & $1.174-1.52$ & .000 \\
\hline Secondary & 3.124 & $2.664-3.663$ & .000 & 3.282 & $2.75-3.92$ & .000 & 2.194 & $1.897-2.537$ & .000 \\
\hline Higher & 8.100 & $5.342-12.282$ & .000 & 5.649 & $4.41-7.25$ & .000 & 3.778 & $2.916-4.894$ & .000 \\
\hline \multicolumn{10}{|l|}{ Husbands education } \\
\hline No education & 1.00 & & & 1.00 & & & 1.00 & & \\
\hline Primary & 1.165 & $1.025-1.323$ & .019 & 1.178 & $1.02-1.36$ & .027 & 1.105 & $.980-1.247$ & .104 \\
\hline Secondary & 1.663 & $1.427-1.937$ & .000 & 1.474 & $1.27-1.72$ & .000 & 1.354 & $1.182-1.551$ & .000 \\
\hline Higher & 2.158 & $1.650-2.823$ & .000 & 2.163 & $1.78-2.63$ & .000 & 1.790 & $1.463-2.191$ & .000 \\
\hline \multicolumn{10}{|c|}{ Respondents work status } \\
\hline Jobless & 1.00 & & & 1.00 & & & 1.00 & & \\
\hline Working & .920 & $.811-1.043$ & .194 & .672 & $.592-.76$ & .000 & .975 & $.871-1.091$ & .653 \\
\hline \multicolumn{10}{|l|}{ Wealth Index } \\
\hline Poor & 1.00 & & & 1.00 & & & 1.00 & & \\
\hline Middle & 1.085 & $.946-1.246$ & .245 & 1.109 & $.959-1.28$ & .162 & .969 & $.853-1.102$ & .635 \\
\hline Rich & 1.498 & $1.292-1.737$ & .000 & 1.393 & $1.21-1.60$ & .000 & 1.061 & $.931-1.209$ & .378 \\
\hline Birth order number & & & & & & & & & \\
\hline First birth & 1.00 & & & 1.00 & & & 1.00 & & \\
\hline More than one & .648 & $.557-.752$ & .000 & .433 & $.383-.49$ & .000 & .598 & $.529-.678$ & .000 \\
\hline Age of respondent at & birth & & & & & & & & \\
\hline$\leq 19$ & 1.00 & & & 1.00 & & & 1.00 & & \\
\hline $20-25$ & 1.058 & $.890-1.258$ & .524 & 1.044 & $.904-1.21$ & .557 & .949 & $.819-1.100$ & .489 \\
\hline$\geq 25$ & 1.045 & $.859-1.270$ & .662 & 1.265 & $1.06-1.50$ & .008 & .983 & $.831-1.164$ & .846 \\
\hline Reading newspaper & & & & & & & & & \\
\hline No & 1.00 & & & 1.00 & & & 1.00 & & \\
\hline Yes & 1.544 & $1.261-1.889$ & .000 & 1.102 & $.967-1.26$ & .144 & 1.072 & $.929-1.237$ & .342 \\
\hline Watching television & & & & & & & & & \\
\hline No & 1.00 & & & 1.00 & & & 1.00 & & \\
\hline Yes & 1.544 & $1.374-1.736$ & .000 & 1.574 & $1.40-1.77$ & .000 & 1.412 & $1.270-1.568$ & .000 \\
\hline Body Mass Index & & & & & & & & & \\
\hline Normal & 1.00 & & & 1.00 & & & 1.00 & & \\
\hline Under-weight & .882 & $.788-.988$ & .029 & .762 & $.679-.856$ & .000 & .857 & $.773-.949$ & .003 \\
\hline Over-weight & 1.798 & $1.473-2.195$ & .000 & 2.280 & $1.990-2.611$ & .000 & 1.853 & $1.593-2.155$ & .000 \\
\hline Person who take hea & ecision & & & & & & & & \\
\hline Women + - Husband & 1.00 & & & 1.00 & & & 1.00 & & \\
\hline Husband only or others & .868 & $.783-.963$ & .008 & .893 & $.811-.984$ & .022 & 1.057 & $.965-1.158$ & .234 \\
\hline
\end{tabular}

urban areas are highly educated and economically stable and they are likely to receive proper antenatal care as well as trained personnel during their delivery and also proper guideline during the postpartum period so we need to give more focus on rural part. Another interesting factor is to access to mass media i.e. television, radio, newspaper because urban women have enough time to access these rather than rural women and this initiated them to receive proper health care.

\section{Special acknowledgement}

We would like to thank the MEASURE DHS for allowing us to use BDHS datasets for analysis. We would also thank the reviewers and editor for their valuable comments, guidance, and suggestions, which helped us to improve the previous version of this paper.

\section{Funding support}

Authors had no funding to conduct this study.

\section{Declaration of competing interest}

The authors declare no conflicts of interests.

\section{References}

1. Okedo-Alex IN, Akamike IC, Ezeanosike OB, Uneke CJ. Determinants of antenatal care utilisation in sub-Saharan Africa: a systematic review. BMJ open. 2019;9(10):e031890.

2. Begum HA, Nili NY, Sayem AM. Utilization of maternal health care services in slum areas of Dhaka city, Bangladesh. Ibrahim Med Coll J. 2010;4(2):44-48.

3. Lomazzi M, Borisch B, Laaser U. The Millennium Development Goals: experiences, 
achievements and what's next. Glob Health Action. 2014;7(1):23695.

4. Chakraborty N, Islam MA, Chowdhury RI, Bari W, Akhter HH. Determinants of the use of maternal health services in rural Bangladesh. Health Promot Int 2003;18(4):327-337.

5. Bangladesh Bureau of Statistics. Statistical Pocket Book. Dhaka: Ministry of Planning, Government of Bangladesh; 2002.

6. National Institute of Population Research. Training (Bangladesh), Mitra and associates (firm). Bangladesh Demographic and Health Survey, 2007. NIPORT. Macro International; 2009.

7. Bangladesh Maternal Mortality and Health Care Survey 2010: Summary of Key Findings and Implications. National Institute of Population Research and Training (NIPORT), MEASURE Evaluation, UNC-CH, USA, ICDDR, B.

8. Tarekegn SM, Lieberman LS, Giedraitis V. Determinants of maternal health service utilization in Ethiopia: analysis of the 2011 Ethiopian Demographic and Health Survey. BMC Pregnancy Childbirth. 2014;14(1):161.

9. Kerber KJ, de Graft-Johnson JE, Bhutta ZA, Okong P, Starrs A, Lawn JE. Continuum of care for maternal, newborn, and child health: from slogan to service delivery. Lancet. 2007;370(9595):1358-1369.

10. National Institute of Population Research and Training. Bangladesh Demographic and Health Survey 2011. Dhaka: National Institute of Population Research and Training; 2013.

11. Bangladesh Demographic and Health Survey 2014: Key Indicators. Dhaka: National Institute of Population Research and Training (NIPORT), Mitra and Associates, and ICF International; 2015 accessed http://dhsprogram.com/pubs/pdf/PR56/PR56.pdf, Accessed date: May 2015.

12. Gabrysch S, Campbell OM. Still too far to walk: literature review of the determinants of delivery service use. BMC Pregnancy Childbirth. 2009;9(1):34.

13. World Health Organization. Reduction of Maternal Mortality: A Joint WHO/UNFPA/ UNICEF/World Bank Statement. Geneva, Switzerland: World Health Organization 1999.

14. National Institute of Population Research and Training. Bangladesh Demographic And Health Survey 2011. Maryland, USA: Calverton; 2013 National Institute of Population Research and Training (NIPORT), Dhaka, Bangladesh; Mitra and Associates, Dhaka, Bangladesh; MEASURE DHS, ICF International.

15. Rowen T, Prata N, Passano P. Evaluation of a traditional birth attendant training programme in Bangladesh. Midwifery. 2011;27(2):229-236.

16. Campbell OM, Graham WJ. Lancet Maternal Survival Series steering group. Strategies for reducing maternal mortality: getting on with what works. Lancet. 2006;368(9543):1284-1299

17. Hurt LS, Alam N, Dieltiens G, Aktar N, Ronsmans C. Duration and magnitude of mortality after pregnancy in rural Bangladesh. Int J Epidemiol. 2008;37(2):397-404.

18. Li XF, Fortney JA, Kotelchuck M, Glover LH. The postpartum period: the key to maternal mortality. Int J Gynecol Obstet. 1996;54(1):1-10.

19. Kim ET, Singh K, Weiss W. Maternal postnatal care in Bangladesh: a closer look specific content and coverage by different types of providers. J Glob Health Rep. $2019 ; 3$.

20. Farah S, Karim M. Determinants of utilization of antenatal care services in rural area of Bangladesh. Bangladesh Med J. 2015;44(2):67-71.

21. Niport M. ICF: Bangladesh Demographic and Health Survey 2014. Dhaka, Bangladesh, and Rockville, Maryland, USA: National Institute of Population Research and Training (NIPORT), Mitra and Associates, and ICF International; 2016 NIPORT, Mitra and Associates, and ICF International. 2013.

22. National Institute of Population Research and Training (NIPORT). Mitra and
Associates and Macro International, Bangladesh Demographic and Health Survey 2011. Maryland, USA: Dhaka, Bangladesh and Calverton; 2013.

23. National Institute of Population Research and Training (NIPORT). Mitra and Associates, Macro International Inc. Bangladesh Demographic and Health Survey 2007. Dhaka, Bangladesh and Calverton. MD: National Institute of Population Research and Training, Mitra and Associates/Macro International; 2009.

24. National Institute of Population Research and Training (NIPORT). Mitra and Associates, Macro International Inc. Bangladesh Demographic and Health Survey 2004. Dhaka, Bangladesh and Calverton. MD: National Institute of Population Research and Training, Mitra and Associates/Macro International; 2005.

25. National Collaborating Centre for Women's. Children's Health (Uk. Antenatal Care: Routine Care for the Healthy Pregnant Woman. RCOG press; 2008.

26. Islam N, Islam MT, Yoshimura Y. Practices and determinants of delivery by skilled birth attendants in Bangladesh. Reprod Health. 2014;11(1):86.

27. World Health Organization. WHO Recommendations on Postnatal Care of the Mother and Newborn. World Health Organization; 2014.

28. Hosmer David W, Lemeshow S. Applied Logistic Regression. New York: Wiley; 2000.

29. Kamal N, Curtis S, Hasan MS, Jamil K. Trends in equity in use of maternal health services in urban and rural Bangladesh. Int J Equity Health. 2016;15(1):27.

30. Hajizadeh M, Alam N, Nandi A. Social inequalities in the utilization of maternal care in Bangladesh: have they widened or narrowed in recent years? Int $J$ Equity Health. 2014;13(1):120

31. Anwar I, Sami M, Akhtar N, et al. Inequity in maternal health-care services: evidence from home-based skilled-birth-attendant programmes in Bangladesh. Bull World Health Organ. 2008;86:252-259.

32. Rahman AE, Perkins J, Islam S, et al. Knowledge and involvement of husbands in maternal and newborn health in rural Bangladesh. BMC Pregnancy Childbirth. 2018;18(1):247

33. Ghose B, Feng D, Tang S, et al. Women's decision-making autonomy and utilisation of maternal healthcare services: results from the Bangladesh Demographic and Health Survey. BMJ open. 2017;7(9):e017142.

34. Ahmed S, Creanga AA, Gillespie DG, Tsui AO. Economic status, education and empowerment: implications for maternal health service utilization in developing countries. PloS One. 2010;5(6):e11190.

35. Fawole OI, Adeoye IA. Women's status within the household as a determinant of maternal health care use in Nigeria. Afr Health Sci. 2015;15(1):217-225.

36. Tiruaynet K, Muchie KF. Determinants of utilization of antenatal care services in Benishangul Gumuz Region, Western Ethiopia: a study based on demographic and health survey. BMC Pregnancy Childbirth. 2019;19(1):115.

37. Mekonnen Y, Mekonnen A. Factors influencing the use of maternal healthcare services in Ethiopia. J Health Popul Nutr. 2003:374-382.

38. Chakraborty N, Islam MA, Chowdhury RI, Bari W, Akhter HH. Determinants of the use of maternal health services in rural Bangladesh. Health Promot Int. 2003;18(4):327-337.

39. Lynch CD, Tumin R, Prasad MR. Association between body mass index and the timing of pregnancy recognition and entry into prenatal care. Obstet Gynecol. 2014;124(5):911-918.

40. Baker EC, Rajasingam D. Using trust databases to identify predictors of late booking for antenatal care within the UK. Publ Health. 2012;126(2):112-116.

41. Babalola S, Fatusi A. Determinants of use of maternal health services in Nigerialooking beyond individual and household factors. BMC Pregnancy Childbirth. 2009;9(1):43. 